Original article

\title{
Perceived discrimination and psychotic experiences in the English general population
}

\author{
Andrew Stickley ${ }^{\mathrm{a}, \mathrm{b}, *}$, Hans $\mathrm{Oh}^{\mathrm{c}}$, Tomiki Sumiyoshi ${ }^{\mathrm{a}}$, Zui Narita ${ }^{\mathrm{d}}$, Jordan E. DeVylder ${ }^{\mathrm{e}}$, \\ Louis Jacob ${ }^{\mathrm{f}, \mathrm{g}}$, Kyle Waldman ${ }^{\mathrm{c}}$, Ai Koyanagig,h
}

a Department of Preventive Intervention for Psychiatric Disorders, National Institute of Mental Health, National Center of Neurology and Psychiatry, Kodaira, Tokyo, Japan

${ }^{\mathrm{b}}$ The Stockholm Center for Health and Social Change (SCOHOST), Södertörn University, Huddinge, Sweden

${ }^{\mathrm{c}}$ University of Southern California, Suzanne Dworak Peck School of Social Work, Los Angeles, CA, USA

d Department of Mental Health, Johns Hopkins Bloomberg School of Public Health, Baltimore, MD, USA

e Graduate School of Social Service, Fordham University, New York, NY, USA

${ }^{\mathrm{f}}$ Faculty of Medicine, University of Versailles Saint-Quentin-en-Yvelines, Montigny-le-Bretonneux 78180, France

${ }^{\mathrm{g}}$ Research and Development Unit, Parc Sanitari Sant Joan de Déu, CIBERSAM, Universitat de Barcelona, Fundació Sant Joan de Déu, Barcelona, Spain

${ }^{\mathrm{h}}$ ICREA, Pg. Lluis Companys 23, Barcelona, Spain

\section{A R T I C L E I N F O}

\section{Article history:}

Received 19 April 2019

Received in revised form 7 August 2019

Accepted 26 August 2019

Available online 14 September 2019

\section{Keywords:}

Delusion

Discrimination

Hallucination

Psychotic experience

\begin{abstract}
A B S T R A C T
Background: Perceived discrimination has been linked to psychotic experiences (PEs). However, as yet, information is lacking on the relationship between different forms of discrimination and PEs. This study examined this association in the English general population.

Methods: Nationally representative, cross-sectional data were analyzed from 7363 adults aged 16 and above that came from the Adult Psychiatric Morbidity Survey, 2007. Self-reported information was obtained on six forms of discrimination (ethnicity, sex, religious beliefs, age, physical health problems/ disability, sexual orientation), while PEs were assessed with the Psychosis Screening Questionnaire (PSQ). Multivariable logistic regression analysis was used to assess associations.

Results: In a fully adjusted logistic regression analysis, any discrimination was significantly associated with PEs (odds ratio [OR]: 2.47, 95\% confidence interval [CI]: 1.75-3.48). All individual forms of discrimination were significantly associated with PEs except sexual orientation. Multiple forms of discrimination were associated with higher odds for PEs in a monotonic fashion with those experiencing $\geq 3$ forms of discrimination having over 5 times higher odds for any PE. In addition, experiencing any discrimination was associated with significantly increased odds for all individual forms of PE with ORs ranging from 2.16 (95\%CI: $1.40-3.35$ ) for strange experience to 3.36 (95\%CI: $1.47-7.76$ ) for auditory hallucination.

Conclusion: Different forms of discrimination are associated with PEs in the general population. As discrimination is common at the societal level, this highlights the importance of public policy and evidence-based interventions to reduce discrimination and improve population mental health.
\end{abstract}

(c) 2019 Elsevier Masson SAS. All rights reserved.

\section{Introduction}

The recognition that psychosis may exist as a continuum of experiences in the general population [1,2] has led to an increasing focus on the social epidemiology of subclinical psychotic experiences (PEs). This research has shown that PEs (hallucinations

\footnotetext{
* Corresponding author at: Department of Preventive Intervention for Psychiatric Disorders, National Institute of Mental Health, National Center of Neurology and Psychiatry, 4-1-1 Ogawahigashi, Kodaira, Tokyo 187-8553, Japan.

E-mail address: amstick66@gmail.com (A. Stickley).
}

and delusions) are common in the general population with a prevalence of around $7 \%$, and share similar socioenvironmental risk factors with psychotic disorders [3]. Importantly, recent research has also highlighted that, like psychotic disorder, PEs might be associated with a number of detrimental outcomes. In particular, PEs have been linked to mental disorders [4], suicidal behavior [5,6], disabilities [7,8], and chronic physical conditions $[9,10]$ as well as an increased risk of mortality [11].

Based on epidemiological evidence that psychosis is more common among minority groups [12,13], and theoretical work linking stress to psychosis etiology [14], there is growing interest in the potential role of perceived discrimination in the occurrence of 
PEs. A study using pooled data from respondents in 19 countries that were collected as part of the World Mental Health Survey found that individuals with PEs had 1.8 times higher odds for reporting discrimination [15]. Cross-sectional research has focused on this association in specific populations and shown that discrimination is associated with PEs among US ethnic adults [16] and Black Americans [17] in a dose-response fashion. Another study reported that discrimination due to sexual orientation partly mediated the association between sexual minority status and PEs in lesbian, gay and bisexual individuals in the Netherlands [18]. Further, longitudinal research has linked perceived discrimination with incident delusional ideation in the Dutch general population [19].

Although the above-mentioned studies have advanced understanding of the association between perceived discrimination and PEs, they have generally viewed discrimination as a phenomenon affecting specific groups and have not distinguished between different types of perceived discrimination in the wider general population. This is an important research gap. Not only are different forms of discrimination common in the general population [20], but they also co-occur in a large number of individuals [21], with research showing that experiencing multiple forms of discrimination is associated with an increased risk for worse mental health (depression/depressive symptoms) compared to experiencing one form [22,23]. Importantly, there is also some evidence that the association may vary between different types of discrimination and mental health outcomes [24] suggesting the need for a focus on specific forms of discrimination (e.g. due to sex, age, ethnicity etc.) in relation to PEs.

Given this, the aim of the current study was to assess the association between perceived discrimination and PEs while considering the type of PE and discrimination using nationally representative data from England. This may be an ideal setting to examine this association as there is evidence that discrimination may be common among different groups [25-27] and that it is associated with worse mental health (common mental disorders) [26].

\section{Method}

\subsection{Participants}

This study used data drawn from the Adult Psychiatric Morbidity Survey, 2007 (APMS). Details of the survey's methodology have been provided elsewhere [28]. The survey was undertaken by the National Center for Social Research and Leicester University during the period from October 2006 to December 2007. The aim was to obtain a nationally representative sample of the English adult population aged 16 and above residing in private households. To do this, multistage stratified probability sampling was used. The sampling frame was the small user Postcode Address File (PAF), while postcode sectors were the primary sampling units (PSUs). Sectors were stratified by region and socioeconomic status. One person was randomly chosen to participate from within each household that was selected. Information was obtained from the respondents using computer-assisted personal interviews (CAPI) and computer-assisted selfinterviews (CASI). The survey response rate was $57 \%$. Weights were generated to ensure that the sample was representative of its intended target population. The Royal Free Hospital and Medical School Research Ethics Committee provided ethical approval for the survey with all participants providing informed consent.

\subsection{Study variables}

\subsubsection{Psychotic experiences (outcome)}

The Psychosis Screening Questionnaire (PSQ), which consists of sections on hypomania, thought control, paranoia, strange experiences, and auditory hallucinations, was used to assess PEs in the past 12 months [29]. Symptom severity was determined by one or two follow-up questions after the main probe question. As in a previous publication using the same dataset, the strictest criteria were used to define the presence of PEs in an attempt to capture truly anomalous experiences [30]. The questions used in the PSQ and the answer options required for the endorsement of PEs can be found in Appendix A. Any PE referred to the endorsement of at least one of the five types of PEs.

\subsubsection{Discrimination (exposure)}

As the questions were considered to be sensitive, perceived discrimination was assessed using CASI. The questions included perceived unfair treatment in the past 12 months in relation to ethnicity (or skin color), sex, religious beliefs, age, physical health problems or disability, sexual orientation, and were based on those developed for the International Social Justice Project [31]. Although information on discrimination due to mental health problems was also available, this item was not used in the current analysis as it may be a consequence of having PEs. The questions and answer options are presented in Appendix B. Any discrimination referred to experiencing at least one of the six abovementioned types of discrimination. The total number of different types of discrimination was also calculated for each participant and categorized as $0,1,2$, and $\geq 3$.

\subsubsection{Control variables}

The selection of the control variables was based on past literature [16,17], and included the following:

2.2.3.1. Sociodemographic indicators. These included variables for sex, age, education [qualification (degree, non-degree, A-level, GCSE, other): yes or no)], ethnicity (white British or other), equivalized income tertiles (high $\geq £ 29826$, middle $£ 14,057$ $<£ 29826$, low $<£ 14,057$ ), and marital status (married/cohabiting or other).

2.2.3.2. Alcohol dependence. Respondents' alcohol consumption was initially assessed with the Alcohol Use Disorders Identification Test (AUDIT) [32]. Individuals who scored $\geq 10$ on this test were additionally assessed for alcohol dependence using the Severity of Alcohol Dependence Questionnaire (SADQ-C) [33], where a score of four and above (out of 60) was used to categorize past 6-month alcohol dependence.

2.2.3.3. Drug use. Each participant was asked if he/she had used one of the following drugs in the past year: cannabis, amphetamines, cocaine, crack, ecstasy, heroin, acid or LSD, magic mushrooms, methadone or physeptone, tranquilizers, amyl nitrate, anabolic steroids, and glues. Those who used at least one of the above-mentioned drugs were considered to be drug users.

2.2.3.4. Social support. The level of social support was assessed by asking the respondents seven questions about whether: (i) family and friends did things to make them happy, (ii) made them feel loved, (iii) could be relied on no matter what, (iv) would see that they were taken care of no matter what, (v) accepted them just the way they are, (vi) made them feel an important part of their lives, and (vii) gave them support and encouragement. The answer options to these questions were provided on a three-point scale: 'not true ( $\operatorname{coded}=0)$ ', 'partly true ( $\operatorname{coded}=1)$ ', or 'certainly true ( coded $=2)$ '. Following a scoring method used in a previous publication [34], the answers to these items were summed to create a scale score that ranged from 0 to 14 with higher scores indicating greater social support (Cronbach's $\alpha=0.88$ ). 
2.2.3.5. Physical health conditions. Details were collected about 20 physical health conditions diagnosed by a doctor or other health care professional that were present in the previous year (cancer, diabetes, epilepsy, migraine, cataracts/eyesight problems, ear/ hearing problems, stroke, heart attack/angina, high blood pressure, bronchitis/emphysema, asthma, allergies, stomach ulcer or other digestive problems, liver problems, bowel/colon problems, bladder problems/incontinence, arthritis, bone/back/joint/muscle problems, infectious disease, and skin problems). The total number of physical health conditions that an individual had was calculated.

2.2.3.6. Common mental disorders. The Clinical Interview Schedule Revised (CIS-R) was used to assess common mental disorders (CMDs): The CIS-R identifies the occurrence of non-psychotic symptoms in the past week to generate ICD-10 diagnoses. Participants who endorsed depressive episode and/or anxiety disorders (generalized anxiety disorder, panic disorder, phobia and obsessive-compulsive disorder) were considered to have CMDs.

\subsection{Statistical analyses}

Analyses were performed with Stata version 14.1 (Stata Corp LP, College Station, Texas). As the focus of the study was on PEs not reaching the clinical threshold for a psychosis diagnosis, those with definite or probable psychosis (definition provided in Appendix C) were excluded from the analysis $(n=40)$. The difference in sample characteristics by the number of different types of discrimination was tested by Chi-square tests and one-way ANOVA for categorical and continuous variables, respectively. Multivariable logistic regression analysis was conducted to assess the association between any discrimination or each individual type of discrimination (exposures) and any PEs (outcome). In order to assess how the inclusion of different control variables affected the association between discrimination and any PE, a hierarchical analysis was conducted where different blocks of variables were entered sequentially. Five different models were constructed: Model 1 adjusted for sex, age, education, ethnicity, income, and marital status; Model 2 - adjusted for the factors in Model 1 and alcohol dependence and drug use; Model 3 - adjusted for the factors in Model 2 and social support; Model 4 - adjusted for the factors in Model 3 and chronic physical conditions; Model 5 - adjusted for the factors in Model 4 and CMDs.

We also assessed the association between any discrimination (exposure) and each PE type (outcome) using multivariable logistic regression analysis while adjusting for all the control variables used in Model 5 described above. Finally, the association between the total number of different types of discrimination $(0,1,2, \geq 3$, exposure) and individual PEs (e.g. hypomania, thought control, paranoia) and any PEs (outcome) was also assessed with the same method.

In all the models, the included covariates were categorical variables except for age, social support, and number of physical health conditions (continuous variables). As a large proportion of the participants provided no information on income (20.7\%), and in order to keep as many respondents in the analysis as possible, we also created a missing category and included it in the analyses. In all analyses, the sample weighting and the complex study design were taken into account with Taylor linearization methods to obtain nationally representative estimates. The results are presented as odds ratios (ORs) with 95\% confidence intervals $(95 \% \mathrm{CI})$. The level of statistical significance was set at $\mathrm{P}<0.05$.

\section{Results}

A total of 7363 individuals aged $\geq 16$ years without a definite or probable psychosis diagnosis were included in the analysis. The mean (SD) age was 46.4 (18.6) years and $51.4 \%$ were female (Table 1 ). The prevalence of any discrimination was $8.3 \%$, while the prevalence of each form of discrimination was: ethnicity $2.7 \%$, sex $1.9 \%$, religious beliefs $1.4 \%$, age $3.3 \%$, physical health problems/ disability $1.7 \%$, and sexual orientation $0.5 \%$. Furthermore, $6.0 \%$, $1.6 \%$, and $0.7 \%$ of the participants experienced 1,2 , and $\geq 3$ different types of discrimination. The prevalence of discrimination was significantly higher among those with PEs falling below $5 \%$ in only one instance (for sexual orientation) whereas for those without PEs

Table 1

Sample characteristics (overall and by the number of different types of discrimination).

\begin{tabular}{|c|c|c|c|c|c|c|c|}
\hline \multirow[b]{2}{*}{ Characteristic } & & \multirow[b]{2}{*}{ Overall } & \multicolumn{4}{|c|}{ Number of different types of discrimination } & \multirow[b]{2}{*}{ P-value ${ }^{a}$} \\
\hline & & & 0 & 1 & 2 & $\geq 3$ & \\
\hline \multirow[t]{2}{*}{ Sex } & Male & 48.6 & 48.4 & 49.3 & 51.6 & 59.9 & 0.585 \\
\hline & Female & 51.4 & 51.6 & 50.7 & 48.4 & 40.1 & \\
\hline Age (years) & Mean (SD) & $46.4(18.6)$ & $47.1(18.6)$ & $39.0(17.3)$ & $34.8(14.6)$ & $33.7(14.3)$ & $<0.001$ \\
\hline \multirow[t]{2}{*}{ Qualifications } & No & 23.9 & 24.6 & 16.6 & 12.2 & 14.7 & 0.001 \\
\hline & Yes & 76.1 & 75.4 & 83.4 & 87.8 & 85.3 & \\
\hline \multirow[t]{2}{*}{ British White } & Yes & 85.1 & 86.8 & 71.3 & 50.9 & 58.0 & $<0.001$ \\
\hline & No & 14.9 & 13.2 & 28.7 & 49.1 & 42.0 & \\
\hline \multirow[t]{3}{*}{ Income } & High & 35.9 & 36.3 & 34.6 & 17.5 & 35.9 & 0.033 \\
\hline & Middle & 32.6 & 32.7 & 30.7 & 39.5 & 18.6 & \\
\hline & Low & 31.5 & 31.0 & 34.7 & 43.1 & 45.4 & \\
\hline \multirow[t]{2}{*}{ Marital status } & Married/cohabiting & 62.9 & 64.7 & 45.0 & 43.3 & 32.0 & $<0.001$ \\
\hline & Other & 37.1 & 35.3 & 55.0 & 56.7 & 68.0 & \\
\hline \multirow[t]{2}{*}{ Alcohol dependence } & No & 94.2 & 94.6 & 90.6 & 86.4 & 87.6 & 0.001 \\
\hline & Yes & 5.8 & 5.4 & 9.4 & 13.6 & 12.4 & \\
\hline \multirow[t]{2}{*}{ Drug use } & No & 90.8 & 91.9 & 78.1 & 86.4 & 71.4 & $<0.001$ \\
\hline & Yes & 9.2 & 8.1 & 21.9 & 13.6 & 28.6 & \\
\hline Social support ${ }^{\mathrm{b}}$ & Mean (SD) & $13.2(1.9)$ & $13.2(1.9)$ & $12.8(2.2)$ & $12.4(2.3)$ & $11.9(2.6)$ & $<0.001$ \\
\hline Number of physical conditions & Mean (SD) & $1.3(1.5)$ & $1.3(1.5)$ & $1.4(1.5)$ & $1.3(1.6)$ & $1.6(1.8)$ & 0.624 \\
\hline \multirow[t]{2}{*}{ Common mental disorders } & No & 92.4 & 93.6 & 80.1 & 81.0 & 64.1 & $<0.001$ \\
\hline & Yes & 7.6 & 6.4 & 19.9 & 19.0 & 35.9 & \\
\hline \multirow[t]{2}{*}{ Any psychotic experience } & No & 94.6 & 95.6 & 85.4 & 82.1 & 64.3 & $<0.001$ \\
\hline & Yes & 5.4 & 4.4 & 14.6 & 17.9 & 35.7 & \\
\hline
\end{tabular}

Abbreviation: SD Standard deviation; Data are percentage unless otherwise stated.

a P-value was calculated by Chi-square test and one-way ANOVA for categorical and continuous variables, respectively.

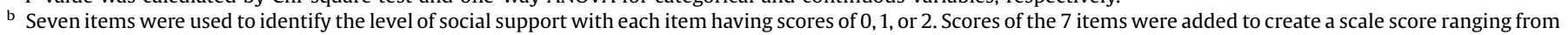
0 to 14 with higher scores corresponding to higher levels of social support. 
it did not exceed 5\% for any of the individual forms of discrimination (see Fig. D1, Appendix D). Overall, $5.4 \%$ of the participants had any PE [hypomania (0.7\%), thought control $(0.8 \%)$, paranoia (1.7\%), strange experience (3.0\%), auditory hallucination $(0.7 \%)]$. The prevalence of PE increased linearly as the number of different forms of discrimination grew, with the prevalence ranging from $4.4 \%$ for those not experiencing discrimination to $35.7 \%$ among those who experienced $\geq 3$ types of discrimination (Table 1). Each form of discrimination was associated with a significantly higher prevalence of any PEs (Fig. 1). In the logistic regression model adjusted for only sociodemographic variables, any discrimination was associated with $3.50(95 \% \mathrm{CI}=2.57-4.76)$ times higher odds for any PE (Model 1) (Table 2). Although this OR was somewhat attenuated after the inclusion of alcohol dependence, drug use, social support, chronic physical conditions, and CMDs in the analysis it remained significant in the fully adjusted Model $5(\mathrm{OR}=2.47 ; 95 \% \mathrm{CI}=1.75-3.48)$. Similar results were obtained for each type of discrimination although the estimates for discrimination due to sexual orientation became non-significant after adjustment for $\mathrm{CMDs}(\mathrm{OR}=1.87 ; 95 \% \mathrm{CI}=0.70-4.98)$. All forms of PE were significantly associated with any discrimination with ORs ranging from 2.16 (strange experience) to 3.36 (auditory hallucination) (Fig. 2). Experiencing an increasing number of different forms of discrimination was associated with increases in the ORs for any PE in a monotonic fashion (Table 3). Specifically, compared to those who did not experience discrimination, the ORs (95\%CI) for 1,2 , and $\geq 3$ types of discrimination were 2.19 (1.503.19), 2.57 (1.27-5.18), and 5.19 (2.44-11.03), respectively. Similar associations were also observed for the individual forms of PE with some exceptions (e.g., thought control).

\section{Discussion}

This study used nationally representative data from 7363 community-based English adults aged 16 and above to examine the association between discrimination and PEs. Plotting the prevalence of $\mathrm{PE}$ by the six individual forms of discrimination showed that PEs were significantly elevated for all types of discrimination. This result was confirmed in a fully adjusted logistic regression analysis where experiencing any discrimination was associated with 2.47 times higher odds for any PE. In the final model all forms of discrimination were linked to significantly higher odds for PE except for discrimination due to sexual orientation, with this non-association possibly resulting from a lack of statistical power, as this was the least frequently reported form of discrimination. The odds for any PE among those who experienced multiple forms of discrimination increased in a monotonic fashion from 2.19 among individuals reporting one form of discrimination to 5.19 for those reporting three or more forms. Finally, experiencing any discrimination was significantly associated with all individual forms of PE with ORs ranging from 2.16 (strange experience) to 3.36 (auditory hallucination).

The associations between (i) any discrimination/individual forms of discrimination and PEs, and (ii) multiple forms of discrimination and increasingly higher odds for PEs, accord with the results from several previous studies [16,17,19,35,36]. For example, in a study that examined the association between discrimination and PEs in multiple ethnic groups, a monotonic association was observed between an increasing discriminatory experience score and higher odds for lifetime PEs [16], while in another study, major racist events were linked to significantly higher odds for lifetime PEs in Black Americans [17].

Perceived discrimination was significantly associated with all forms of PE, especially thought control and auditory hallucinations. Findings from earlier studies have produced mixed results for the association between discrimination and individual psychotic experiences. A study among four ethnic groups in the United States that used a pooled sample found a significant association between discrimination and both (visual and auditory) hallucinations, and delusions [16]. In contrast, other research undertaken in the Netherlands among the general population [19] and ethnic minority adolescents [35] showed that personal discrimination was associated with delusions but not hallucinations. Oh and colleagues have highlighted that the association may be even more

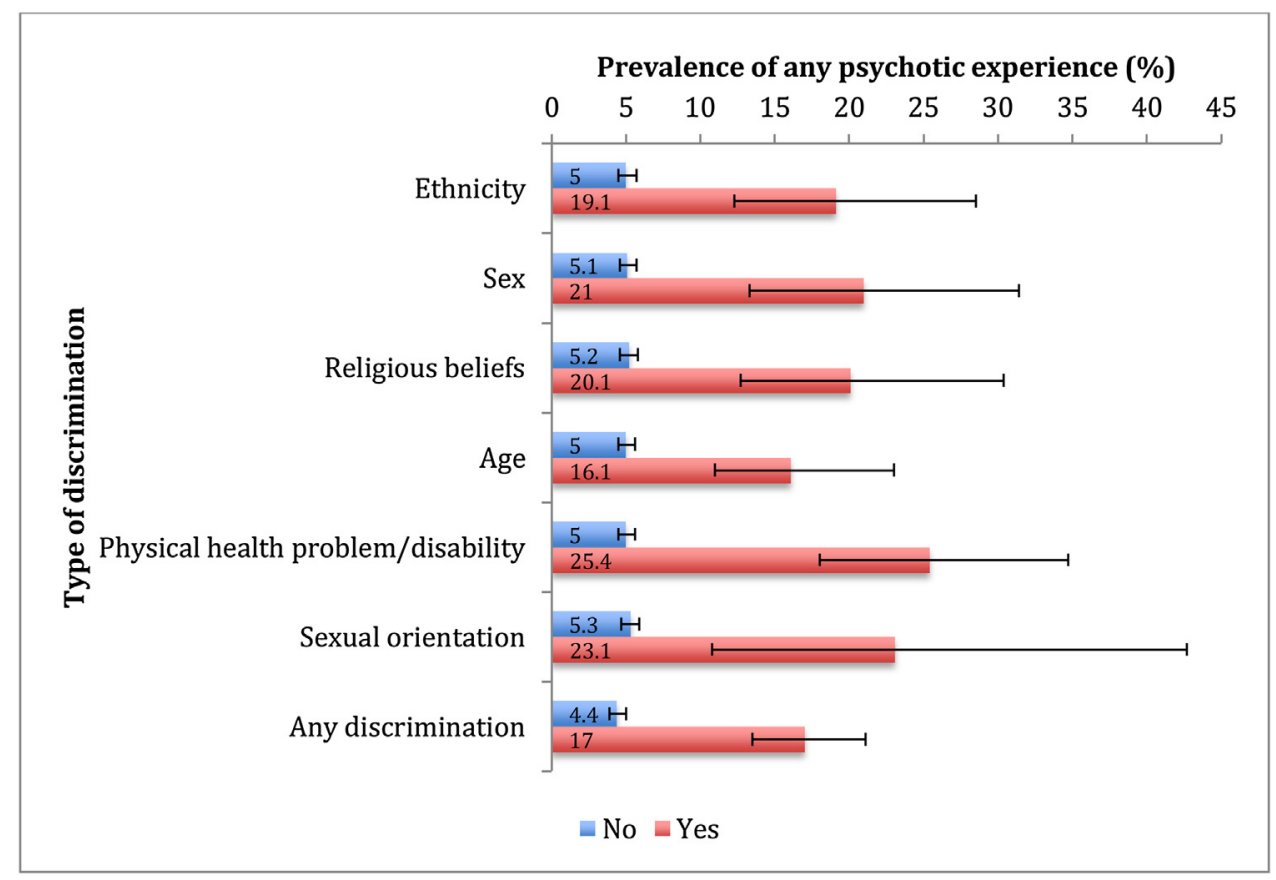

Fig. 1. Prevalence of any psychotic experience by type of discrimination. Bars denote $95 \%$ confidence intervals. 
Table 2

Association between discrimination and any psychotic experience estimated by multivariable logistic regression.

\begin{tabular}{|c|c|c|c|c|c|}
\hline Type of discrimination & $\begin{array}{l}\text { Model } 1 \\
\text { OR [95\%CI] }\end{array}$ & $\begin{array}{l}\text { Model } 2 \\
\text { OR [95\%CI] }\end{array}$ & $\begin{array}{l}\text { Model } 3 \\
\text { OR [95\%CI] }\end{array}$ & $\begin{array}{l}\text { Model } 4 \\
\text { OR [95\%CI] }\end{array}$ & $\begin{array}{l}\text { Model } 5 \\
\text { OR [95\%CI] }\end{array}$ \\
\hline Ethnicity & $\begin{array}{l}3.28^{* * *} \\
{[1.94,5.56]}\end{array}$ & $\begin{array}{l}3.33^{* * * *} \\
{[1.98,5.61]}\end{array}$ & $\begin{array}{l}3.18^{* * *} \\
{[1.88,5.39]}\end{array}$ & $\begin{array}{l}3.28^{* * *} \\
{[1.92,5.61]}\end{array}$ & $\begin{array}{l}2.80^{* * *} \\
{[1.64,4.77]}\end{array}$ \\
\hline Sex & $\begin{array}{l}3.75^{* * *} \\
{[2.11,6.66]}\end{array}$ & $\begin{array}{l}3.42^{* * *} \\
{[1.91,6.14]}\end{array}$ & $\begin{array}{l}3.12^{* * *} \\
{[1.71,5.69]}\end{array}$ & $\begin{array}{l}3.04^{* * *} \\
{[1.65,5.60]}\end{array}$ & $\begin{array}{l}2.41^{* *} \\
{[1.31,4.42]}\end{array}$ \\
\hline Religious beliefs & $\begin{array}{l}3.27^{* * *} \\
{[1.75,6.10]}\end{array}$ & $\begin{array}{l}3.04^{* * *} \\
{[1.62,5.71]}\end{array}$ & $\begin{array}{l}2.83^{* *} \\
{[1.51,5.29]}\end{array}$ & $\begin{array}{l}2.71^{* *} \\
{[1.42,5.14]}\end{array}$ & $\begin{array}{l}2.30^{*} \\
{[1.13,4.68]}\end{array}$ \\
\hline Age & $\begin{array}{l}2.95^{* * *} \\
{[1.85,4.71]}\end{array}$ & $\begin{array}{l}2.71^{* * *} \\
{[1.68,4.37]}\end{array}$ & $\begin{array}{l}2.63^{* * *} \\
{[1.60,4.32]}\end{array}$ & $\begin{array}{l}2.51^{* * *} \\
{[1.52,4.13]}\end{array}$ & $\begin{array}{l}2.29^{* *} \\
{[1.34,3.89]}\end{array}$ \\
\hline Physical health problems or disability & $\begin{array}{l}5.41^{* * *} \\
{[3.47,8.45]}\end{array}$ & $\begin{array}{l}5.33^{* * * *} \\
{[3.37,8.42]}\end{array}$ & $\begin{array}{l}4.86^{* * *} \\
{[3.05,7.72]}\end{array}$ & $\begin{array}{l}3.86^{* * *} \\
{[2.37,6.28]}\end{array}$ & $\begin{array}{l}2.97^{* * *} \\
{[1.76,5.03]}\end{array}$ \\
\hline Sexual orientation & $\begin{array}{l}3.40^{*} \\
{[1.32,8.80]}\end{array}$ & $\begin{array}{l}3.02^{*} \\
{[1.24,7.36]}\end{array}$ & $\begin{array}{l}2.77^{*} \\
{[1.20,6.42]}\end{array}$ & $\begin{array}{l}2.33^{*} \\
{[1.01,5.39]}\end{array}$ & $\begin{array}{l}1.87 \\
{[0.70,4.98]}\end{array}$ \\
\hline Any discrimination & $\begin{array}{l}3.50^{* * *} \\
{[2.57,4.76]}\end{array}$ & $\begin{array}{l}3.27^{* * *} \\
{[2.39,4.49]}\end{array}$ & $\begin{array}{l}3.12^{* * *} \\
{[2.26,4.31]}\end{array}$ & $\begin{array}{l}2.93^{* * *} \\
{[2.12,4.05]}\end{array}$ & $\begin{array}{l}2.47^{* * *} \\
{[1.75,3.48]}\end{array}$ \\
\hline
\end{tabular}

Abbreviation: OR Odds ratio; CI Confidence interval.

Model 1: sex, age, education, ethnicity, income, and marital status.

Model 2: adjusted for factors in Model 1, alcohol dependence, and drug use.

Model 3: adjusted for factors in Model 2 and social support.

Model 4: adjusted for factors in Model 3 and chronic physical conditions.

Model 5: adjusted for factors in Model 4 and common mental disorders.

${ }^{*} \mathrm{p}<0.05,{ }^{* *} \mathrm{p}<0.01,{ }^{* * *} \mathrm{p}<0.001$.

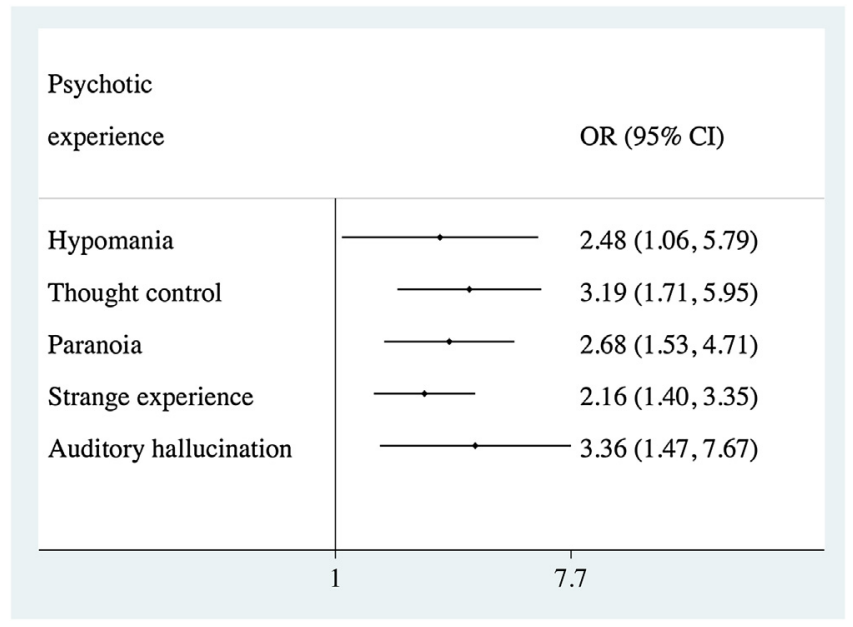

Fig. 2. Association between any discrimination (exposure) and different types of psychotic experience (outcome) estimated by multivariable logistic regression. Abbreviation: OR Odds ratio; $\mathrm{CI}$ Confidence interval

Models were adjusted for sex, age, education, ethnicity, education, income, marital status, alcohol dependence, drug use, social support, chronic physical conditions, and common mental disorders. nuanced by showing that individual racist events were associated with delusions and visual hallucinations but not auditory hallucinations in Black American adults [17]. It is unclear if these study-wide differences result from methodological factors, e.g. the way discrimination is measured and operationalized, differences in the subjective impact of different forms of discrimination [17], or whether discrimination and its effects are modified by contextual factors [19]. For example, as a recent study linked weak ethnic identity to hallucinatory but not delusional experiences in Dutch ethnic minority adolescents [35], it is possible that similar factors might also be important for variations in the association between discrimination and different forms of PE in the wider general population. Given the mixed findings across studies, an important task for future research will be to determine if the association between discrimination and individual PEs varies within and across settings and the factors associated with any variation.

Although the exact mechanisms linking perceived discrimination and PEs are unknown, several factors may be involved. For instance, previous research has highlighted that discrimination is a stressor $[37,38]$ that can affect the functioning of the hypothalamic-pituitary-adrenal (HPA) axis [39]. Given this, the 'neural diathesis stress model', which has hypothesized that psychosocial stress may be central in the emergence of

Table 3

Association between total number of different types of discrimination and psychotic experiences estimated by multivariable logistic regression.

\begin{tabular}{|c|c|c|c|c|c|c|}
\hline $\begin{array}{l}\text { Number of } \\
\text { types of discrimination }\end{array}$ & OR [95\%CI] & $\begin{array}{l}\text { Thought control } \\
\text { OR }[95 \% \mathrm{CI}]\end{array}$ & $\begin{array}{l}\text { Paranoia } \\
\text { OR [95\%CI] }\end{array}$ & $\begin{array}{l}\text { Strange } \\
\text { experience } \\
\text { OR [95\%CI] }\end{array}$ & $\begin{array}{l}\text { Auditory } \\
\text { hallucination } \\
\text { OR }[95 \% \mathrm{CI}]\end{array}$ & $\begin{array}{l}\text { Any psychotic } \\
\text { experience } \\
\text { OR }[95 \% \mathrm{CI}]\end{array}$ \\
\hline 0 & 1.00 & 1.00 & 1.00 & 1.00 & 1.00 & 1.00 \\
\hline 1 & $\begin{array}{l}1.07 \\
{[0.19,6.05]}\end{array}$ & $\begin{array}{l}2.78^{* *} \\
{[1.38,5.61]}\end{array}$ & $\begin{array}{l}2.27^{* *} \\
{[1.25,4.12]}\end{array}$ & $\begin{array}{l}1.99^{* *} \\
{[1.23,3.21]}\end{array}$ & $\begin{array}{l}2.71^{*} \\
{[1.03,7.11]}\end{array}$ & $\begin{array}{l}2.19^{* * *} \\
{[1.50,3.19]}\end{array}$ \\
\hline 2 & $\begin{array}{l}4.45^{*} \\
{[1.29,15.35]}\end{array}$ & $\begin{array}{l}5.65^{* *} \\
{[1.71,18.67]}\end{array}$ & $\begin{array}{l}2.71^{*} \\
{[1.04,7.07]}\end{array}$ & $\begin{array}{l}2.33 \\
{[0.89,6.11]}\end{array}$ & $\begin{array}{l}2.61 \\
{[0.59,11.57]}\end{array}$ & $\begin{array}{l}2.57^{* *} \\
{[1.27,5.18]}\end{array}$ \\
\hline$\geq 3$ & $\begin{array}{l}12.21^{* * *} \\
{[3.75,39.74]}\end{array}$ & $\begin{array}{l}2.05 \\
{[0.38,11.14]}\end{array}$ & $\begin{array}{l}6.00^{* *} \\
{[1.80,19.98]}\end{array}$ & $\begin{array}{l}3.22^{*} \\
{[1.10,9.37]}\end{array}$ & $\begin{array}{l}11.13^{* *} \\
{[2.20,56.35]}\end{array}$ & $\begin{array}{l}5.19 * * * \\
{[2.44,11.03]}\end{array}$ \\
\hline
\end{tabular}

Abbreviation: OR Odds ratio; CI Confidence interval.

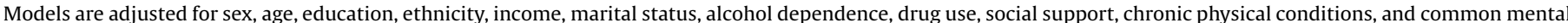
disorders.

${ }^{*} \mathrm{p}<0.05,{ }^{* *} \mathrm{p}<0.01$, *** $\mathrm{p}<0.001$. 
psychotic symptoms through the effects it has on the HPA axis [14], might be important in this context. Alternatively, discrimination may be a potential marker of 'social defeat' [40], that is, a subordinate/excluded status (from the majority group), the long-term effects of which might result in an increased risk for psychosis, possibly through dysregulation of the dopamine system [41,42]. It has also been suggested that the experience of discrimination may affect cognitive attributions, which have been implicated in the emergence of delusions such as paranoia [19].

This study has several strengths. To the best of our knowledge, it is the first study to examine the association between several individual forms of discrimination and PEs using data from a large, nationally representative populationbased sample, while controlling for several covariates including CMDs. It should be recognized however, that there are also some study limitations. First, information on different forms of discrimination was collected using single-item questions. This may have been problematic as there is some evidence that such measures may result in discrimination being underreported [43]. Indeed, discrimination is a complex phenomenon that is often measured using multiple-item scales [44]. A more detailed examination of the form and effects of discrimination would have helped us understand the association between discrimination and PEs more thoroughly. Future studies should use more comprehensive measures when examining the association between PEs and discrimination. Second, this study relied on self-reports of discrimination that may result in underreporting because of socially desirable responding [45]. Third, the study sample was restricted to residential respondents. As there is some evidence that both psychotic symptoms [46] and discrimination [47] may be prevalent among those who are homeless, this highlights the necessity for future research to examine this association in all societal groups to gain a more complete understanding of it. Lastly, the data we used in this study were cross-sectional, so we were not able to determine causality or the direction of the associations. It is possible for example, that persecutory delusions might increase the possibility of perceiving discrimination [16].

In conclusion, this study showed that in a general population sample, different forms of discrimination were significantly associated with PEs, with a similar strength of association across different exposures, while co-occurring forms of discrimination were associated with higher odds for PEs in a monotonic fashion. Given the high prevalence of different forms of discrimination in the general population, as well as their co-occurrence, the results of this study highlight the importance of reducing all forms of discrimination at the societal level to improve public mental health. Both public policy and evidence-based interventions should now be formulated to achieve this goal.

\section{Declaration of Competing Interest}

None.

\section{Acknowledgements}

We would like to thank the National Center for Social Research and the University of Leicester who were the Principal Investigators of this survey. In addition, we would also like to thank the UK Data Archive and the National Center for Social Research as the data collectors and for making these data publicly available. They bear no responsibility for this analysis or interpretation of this publicly available dataset. This research did not receive any specific grant from funding agencies in the public, commercial, or not-forprofit sectors.
Appendix A. Questions on psychotic experiences and responses required for endorsement based on the Psychosis Screening Questionnaire

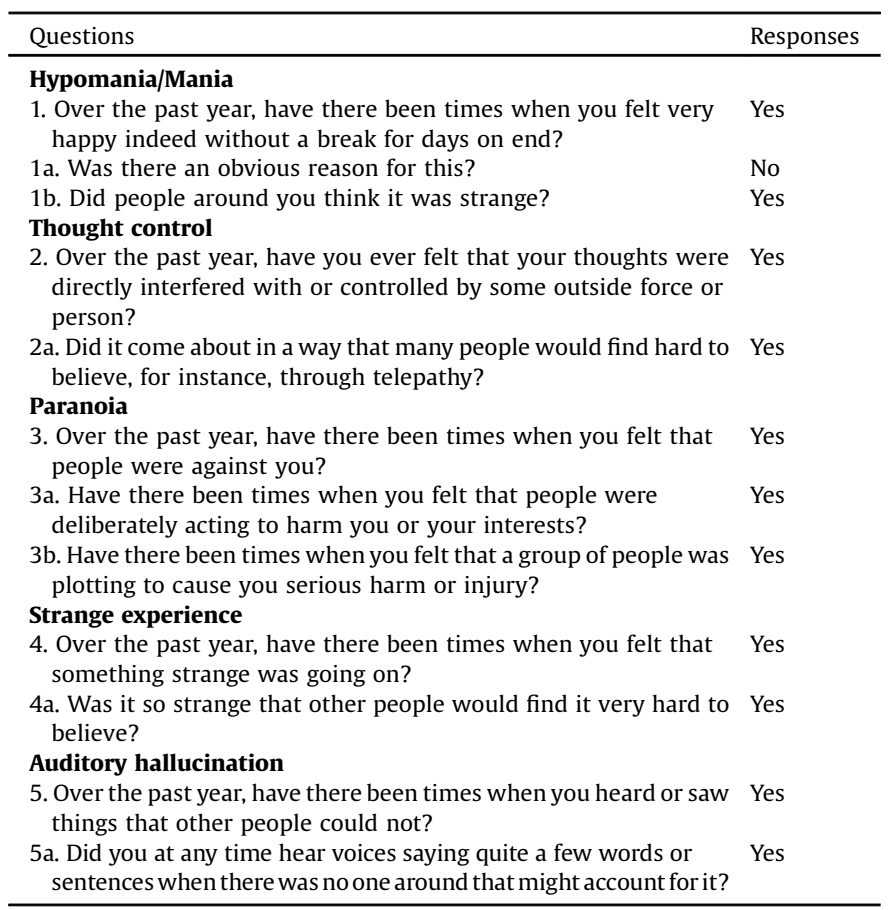

The skip pattern was the following: If yes to 1, then asked 1a. If no to $1 \mathrm{a}$, then asked $1 \mathrm{~b}$; If yes to 2 , then asked $2 \mathrm{a}$; If yes to 3 , then asked 3a; If yes to $3 a$, then asked $3 b$; If yes to 4 , then asked $4 a$; If yes to 5 , then asked 5 a.

\section{Appendix B}

\section{Discrimination questions and answer options}

The next questions are about whether you have been unfairly treated in any aspect of your life, because you belong to a particular group.

Have you been unfairly treated in the last 12 months, that is since (date), because of your skin

colour or ethnicity?

Yes

No

Don't Understand/Does Not Apply

Have you been unfairly treated in the last 12 months, that is since (date), because of your sex?

Yes

No

Don't Understand/Does Not Apply

Have you been unfairly treated in the last 12 months, that is since (date), because of your religious beliefs?

Yes

No

Don't Understand/Does Not Apply

Have you been unfairly treated in the last 12 months, that is since (date), because of your age?

Yes

No

Don't Understand/Does Not Apply

Have you been unfairly treated in the last 12 months, that is since (date), because of any other

[physical] health problem or disability? 
Yes

No

Don't Understand/Does Not Apply

Have you been unfairly treated in the last 12 months, that is since (date), because of your sexual orientation?

Yes

No

Don't Understand/Does Not Apply

\section{Appendix C}

Definition of definite or probable psychosis

Individuals fulfilling at least one of the four phase-one psychosis screening criteria (current antipsychotic use, hospitalization for mental problems, endorsement of the question on auditory hallucinations of the PSQ ("Did you at any time hear voices saying quite a few words or sentences when there was no one around that might account for it?"), and self-reported diagnosis or symptoms of psychosis) were invited for a phase-two assessment. A definitive diagnosis of psychosis (schizophrenia and affective psychosis) was based on the Schedules for Clinical Assessment in Neuropsychiatry (SCAN, version 2.1) (1) conducted in phase-two by a clinical interviewer. However, since $39 \%$ of those individuals invited for a phase-two interview either refused or could not be contacted, a 'probable psychosis' measure was also created for individuals without a phase-two interview but who fulfilled at least two of the phase-one psychosis screening criteria (2).

(1)World Health Organization. SCAN: Schedules for Clinical Assessment in Neuropsychiatry. 1992.

(2)McManus S, Meltzer H, Brugha T, Bebbington P, Jenkins R. Adult Psychiatric Morbidity in England, 2007: Results of a Household Survey. London: 2009.

\section{Appendix D}

\section{References}

[1] Johns LC, van Os J. The continuity of psychotic experiences in the general population. Clin Psychol Rev 2001;21:1125-41.

[2] van Os J. Is there a continuum of psychotic experiences in the general population? Epidemiol Psichiatr Soc 2003:12:242-52.

[3] van Os J, Reininghaus U. Psychosis as a transdiagnostic and extended phenotype in the general population. World Psychiatry 2016;15:118-24.

[4] McGrath JJ, Saha S, Al-Hamzawi A, Andrade L, Benjet C, Bromet EJ, et al. The bidirectional associations between psychotic experiences and DSM-IV mental disorders. Am J Psychiatry 2016;173:997-1006.

[5] Yates K, Lang U, Cederlof M, Boland F, Taylor P, Cannon M, et al. Association of psychotic experiences with subsequent risk of suicidal ideation, suicide attempts, and suicide deaths: a systematic review and meta-analysis of longitudinal population studies. JAMA Psychiatry 2019;76:180-9.

[6] DeVylder JE, Lukens EP, Link BG, Lieberman JA. Suicidal ideation and suicide attempts among adults with psychotic experiences: data from the Collaborative Psychiatric Epidemiology Surveys. JAMA Psychiatry 2015;72:219-25.

[7] Navarro-Mateu F, Alonso J, Lim CCW, Saha S, Aguilar-Gaxiola S, Al-Hamzawi A, et al. The association between psychotic experiences and disability: results from the WHO World Mental Health Surveys. Acta Psychiatr Scand 2017; 136:74-84.

[8] Oh H, Koyanagi A, Kelleher I, DeVylder J. Psychotic experiences and disability: findings from the Collaborative Psychiatric Epidemiology Surveys. Schizophr Res 2018;193:343-7.

[9] Moreno C, Nuevo R, Chatterii S, Verdes E, Arango C, Ayuso-Mateos JL. Psychotic symptoms are associated with physical health problems independently of a mental disorder diagnosis: results from the WHO World Health Survey. World Psychiatry 2013;12:251-7.

[10] Oh H, Waldman K, Stickley A, DeVylder JE, Koyanagi A. Psychotic experiences and physical health conditions in the United States. Compr Psychiatry 2019;90:1-6.

[11] Sharifi V, Eaton WW, Wu LT, Roth KB, Burchett BM, Mojtabai R. Psychotic experiences and risk of death in the general population: 24-27 year follow-up of the Epidemiologic Catchment Area study. Br J Psychiatry 2015;207:30-6.

[12] Veling W, Susser E, van Os J, Mackenbach JP, Selten JP, Hoek HW. Ethnic density of neighborhoods and incidence of psychotic disorders among immigrants. Am J Psychiatry 2008;165:66-73.

[13] Bresnahan M, Begg MD, Brown A, Schaefer C, Sohler N, Insel B, et al. Race and risk of schizophrenia in a US birth cohort: another example of health disparity? Int J Epidemiol 2007;36:751-8.

[14] Walker E, Mittal V, Tessner K. Stress and the hypothalamic pituitary adrenal axis in the developmental course of schizophrenia. Annu Rev Clin Psychol 2008;4:189-216.

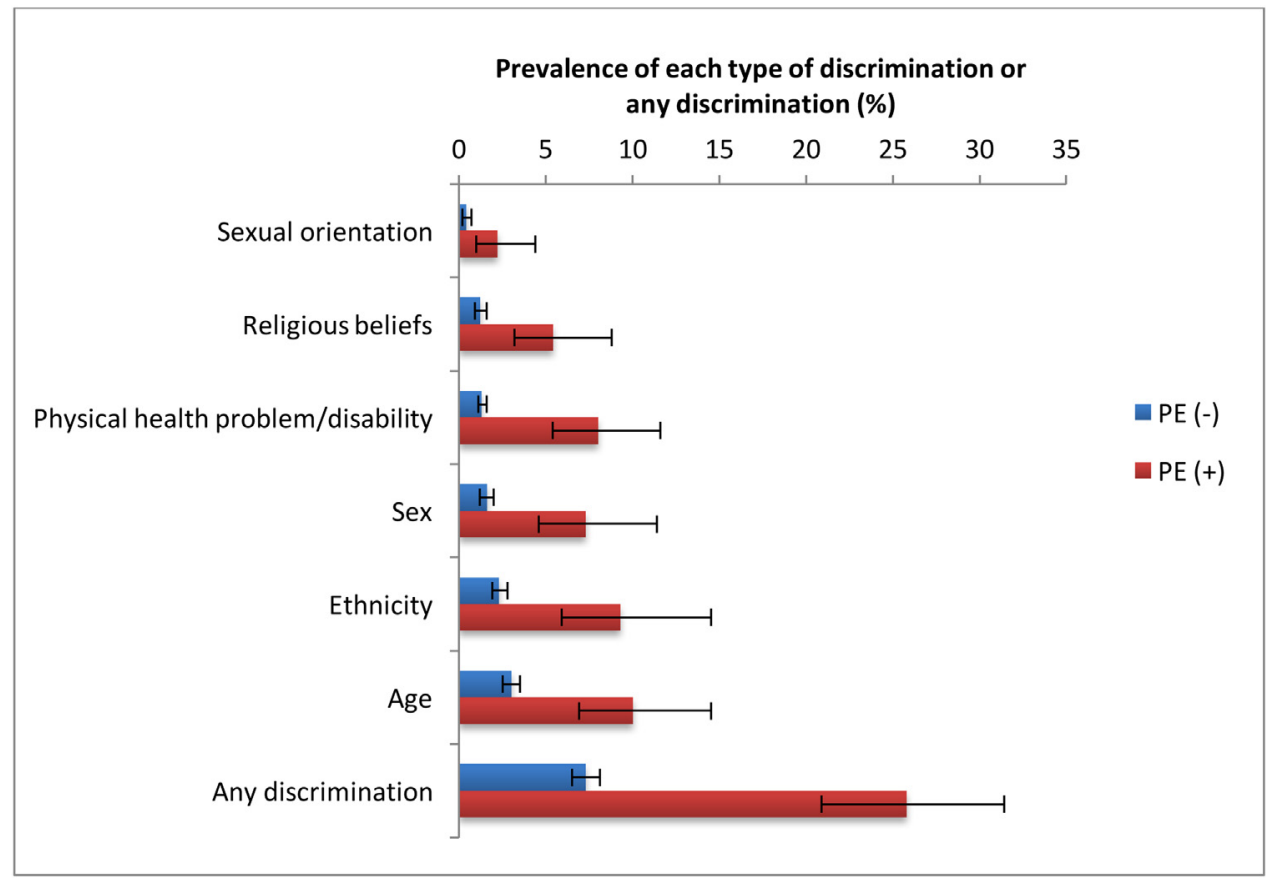

Fig. D1. Prevalence of each type of discrimination or any discrimination by presence or absence of psychotic experiences. Abbreviation: PE Psychotic experiences Bars denote $95 \%$ confidence interval. 
[15]

Alonso J, Saha S, Lim CCW, Aguilar-Gaxiola S, Al-Hamzawi A, Benjet C, et al. The association between psychotic experiences and health-related quality of life: a cross-national analysis based on World Mental Health Surveys. Schizophr Res 2018;201:46-53.

[16] Oh H, Yang LH, Anglin DM, DeVylder JE. Perceived discrimination and psychotic experiences across multiple ethnic groups in the United States. Schizophr Res 2014;157:259-65.

[17] Oh H, Cogburn CD, Anglin D, Lukens E, DeVylder J. Major discriminatory events and risk for psychotic experiences among Black Americans. Am J Orthopsychiatry 2016;86:277-85.

[18] Gevonden MJ, Selten JP, Myin-Germeys I, de Graaf R, ten Have M, van Dorsselaer S, et al. Sexual minority status and psychotic symptoms: findings from the Netherlands Mental Health Survey and Incidence Studies (NEMESIS). Psychol Med 2014;44:421-33.

[19] Janssen I, Hanssen M, Bak M, Bijl RV, de Graaf R, Vollebergh W, et al. Discrimination and delusional ideation. Br J Psychiatry 2003;182:71-6.

[20] Kessler RC, Mickelson KD, Williams DR. The prevalence, distribution, and mental health correlates of perceived discrimination in the United States. J Health Soc Behav 1999;40:208-30.

[21] Puhl RM, Andreyeva T, Brownell KD. Perceptions of weight discrimination: prevalence and comparison to race and gender discrimination in America. Int J Obes 2008;32:992-1000.

[22] Grollman EA. Multiple forms of perceived discrimination and health among adolescents and young adults. J Health Soc Behav 2012;53:199-214.

[23] Grollman EA. Multiple disadvantaged statuses and health: the role of multiple forms of discrimination. J Health Soc Behav 2014;55:3-19.

[24] Bostwick WB, Boyd CJ, Hughes TL, West BT, McCabe SE. Discrimination and mental health among lesbian, gay, and bisexual adults in the United States. Am J Orthopsychiatry 2014;84:35-45.

[25] Corker E, Hamilton S, Henderson C, Weeks C, Pinfold V, Rose D, et al. Experiences of discrimination among people using mental health services in England 2008-2011. Br J Psychiatry Suppl 2013;202:s58-63.

[26] Karlsen S, Nazroo JY, McKenzie K, Bhui K, Weich S. Racism, psychosis and common mental disorder among ethnic minority groups in England. Psychol Med 2005;35:1795-803.

[27] Rippon I, Kneale D, de Oliveira C, Demakakos P, Steptoe A. Perceived age discrimination in older adults. Age Ageing 2014;43:379-86.

[28] McManus S, Meltzer H, Brugha T, Bebbington P, Jenkins R. Adult psychiatric morbidity in England, 2007: results of a household survey. London 2009.

[29] Bebbington P. Nayani T. The psychosis screening questionnaire. Int J Methods Psychiatr Res 1995;5:11-9.

[30] Boyda D, McFeeters D. Childhood maltreatment and social functioning in adults with sub-clinical psychosis. Psychiatry Res 2015;226:376-82.

[31] Wegener B, Mason D, International Social Justice Project (ISJP). International social justice project, 1991 and 1996. Ann Arbor, MI: Inter-university Consortium for Political and Social Research (ICPSR); 2010.
[32] Saunders JB, Aasland OG, Babor TF, de la Fuente JR, Grant M. Development of the Alcohol Use Disorders Identification Test (AUDIT): WHO collaborative project on early detection of persons with harmful alcohol consumption-II. Addiction 1993;88:791-804.

[33] Stockwell T, Sitharthan T, McGrath D, Lang E. The measurement of alcohol dependence and impaired control in community samples. Addiction 1994;89:167-74.

[34] Wickham S, Taylor P, Shevlin M, Bentall RP. The impact of social deprivation on paranoia, hallucinations, mania and depression: the role of discrimination social support, stress and trust. PLoS One 2014;9:e105140.

[35] El Bouhaddani S, van Domburgh L, Schaefer B, Doreleijers TAH, Veling W. Psychotic experiences among ethnic majority and minority adolescents and the role of discrimination and ethnic identity. Soc Psychiatry Psychiatr Epidemiol 2019;54:343-53.

[36] van de Beek MH, van der Krieke L, Schoevers RA, Veling W. Social exclusion and psychopathology in an online cohort of Moroccan-Dutch migrants: results of the MEDINA-study. PLoS One 2017;12:e0179827.

[37] Clark R, Anderson NB, Clark VR, Williams DR. Racism as a stressor for African Americans. A biopsychosocial model. Am Psychol 1999;54:805-16.

[38] Meyer IH. Prejudice and discrimination as social stressors. In: Meyer IH, Northridge ME, editors. The health of sexual minorities. Boston, MA: Springer; 2007. p. 242-67.

[39] Busse D, Yim IS, Campos B, Marshburn CK. Discrimination and the HPA axis: current evidence and future directions. J Behav Med 2017;40:539-52.

[40] Selten JP, van der Ven E, Rutten BP, Cantor-Graae E. The social defeat hypothesis of schizophrenia: an update. Schizophr Bull 2013;39:1180-6.

[41] Selten JP, Booij J, Buwalda B, Meyer-Lindenberg A. Biological mechanisms whereby social exclusion may contribute to the etiology of psychosis: a narrative review. Schizophr Bull 2017;43:287-92.

[42] Selten JP, Cantor-Graae E. Social defeat: risk factor for schizophrenia? Br J Psychiatry 2005;187:101-2.

[43] Gee GC, Ro A, Shariff-Marco S, Chae D. Racial discrimination and health among Asian Americans: evidence, assessment, and directions for future research. Epidemiol Rev 2009;31:130-51.

[44] Atkins R. Instruments measuring perceived racism/racial discrimination: review and critique of factor analytic techniques. Int J Health Serv 2014;44:711-34.

[45] Krieger N, Smith K, Naishadham D, Hartman C, Barbeau EM. Experiences of discrimination: validity and reliability of a self-report measure for population health research on racism and health. Soc Sci Med 2005;61:1576-96.

[46] Mundy P, Robertson M, Robertson J, Greenblatt M. The prevalence of psychotic symptoms in homeless adolescents. J Am Acad Child Adolesc Psychiatry 1990;29:724-31.

[47] Milburn NG, Batterham P, Ayala G, Rice E, Solorio R, Desmond K, et al. Discrimination and mental health problems among homeless minority young people. Public Health Rep 2010;125:61-7. 